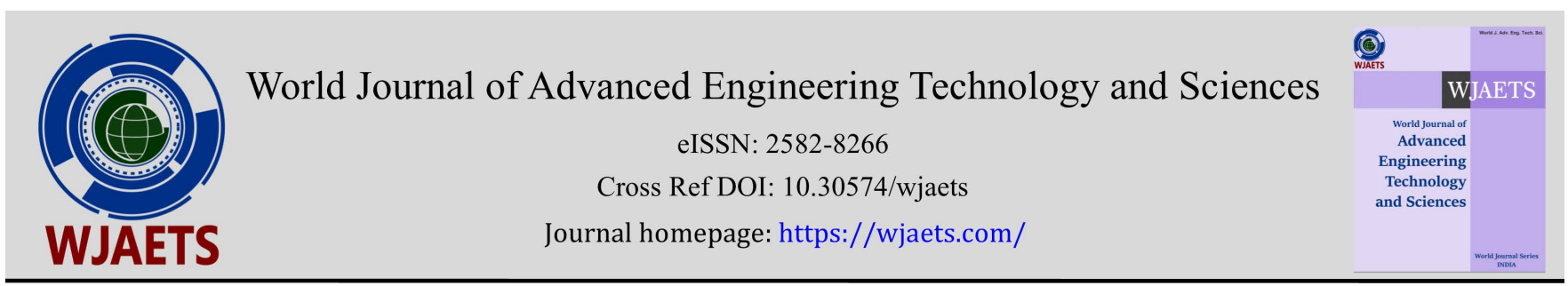

(RESEARCH ARTICLE)

\title{
A study of the microstructure of a bio-ash stabilized sandy clay soil
}

\author{
Apampa O Ahmed *, Oseni Kehinde and Popoola Monsuru \\ Civil Engineering Department, School of Engineering, Moshood Abiola Polytechnic, Abeokuta, Nigeria.
}

World Journal of Advanced Engineering Technology and Sciences, 2021, 02(02), 042-051

Publication history: Received on 01 March 2021; revised on 29 April 2021; accepted on 01 May 2021

Article DOI: https://doi.org/10.30574/wjaets.2021.2.2.0028

\begin{abstract}
This research work studies the microstructure of a sandy-clay soil as it is stabilized with corn cob ash (CCA) in dosage rates of $0-3 \%$, in steps of $0.5 \%$, and comparing with OPC-CCA blends (2:1) and OPC alone. The aim being to study the progressive flocculation and agglomeration of the molecules of the soil, upon the addition of varying blends of CCA- OPC in small doses. The samples were taken for microstructural examination using the scanning electron microscope (SEM), and for elemental composition using the Energy Dispersive X-ray Spectroscope (EDS). Corresponding samples of the stabilized soil were subjected to the unconfined compressive strength (UCS) tests. The cat-ion exchange capacity of the soil was also computed. The SEM images indicate that for the CCA stabilized soil, the lattice structure of soil molecules is most clearly defined at 1\% CCA content. This is comparable to the cat-ion exchange capacity of the soil (1.17\%), and also corresponds to the point of maximum UCS $(313.7 \mathrm{KN} / \mathrm{m} 2)$. Significantly, the UCS value returned for CCA stabilized soil was higher than that for OPC alone and for the OPC-CCA blend, within the test range of this study. The paper concludes that a significant level of stabilization could be attained with this soil type, with small doses of CCA, without the need for OPC, whose effect is more pronounced at higher doses and at the pozzolanic phase.
\end{abstract}

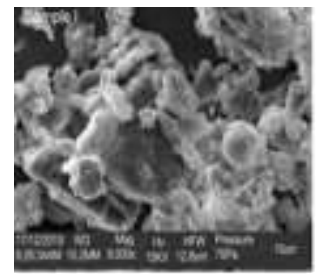

$0 \%$ CCA

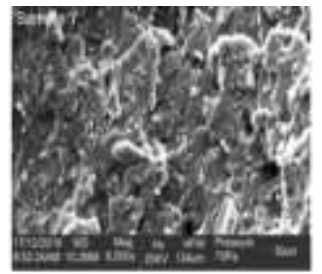

$0.5 \%$ CCA

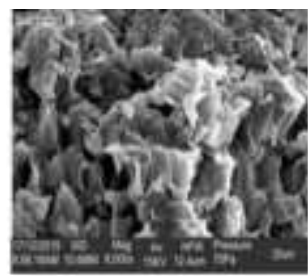

$1.0 \%$ CCA

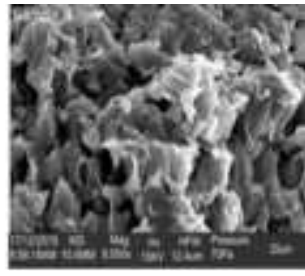

$1.5 \%$ CCA

Keywords: Corn cob ash; Lateritic soil; Microstructure; Stabilization; Unconfined compressive strength

\section{Introduction}

\subsection{Background}

Soils are the major constituents of roads, dams, embankments and other major engineering structures and infrastructure. Their suitability for purpose is often assessed not only in terms of the mechanical properties and strength parameters, but also in terms of the economics of hauling the soil materials to site. Where suitable materials are not readily available, engineers have had to deploy various soil improvement techniques to the readily available soil. One of these methods is the stabilization of the soil by the addition of a suitable binder, the most common of which is Ordinary Portland Cement (OPC).

\footnotetext{
${ }^{*}$ Corresponding author: Apampa O Ahmed; Tel +234 (0) 8061664780; Email: Apampa.olanrewaju@mapoly.edu.ng Civil Engineering Department, School of Engineering, Moshood Abiola Polytechnic, Abeokuta, Nigeria. 
However, increasing global concerns with anthropogenic carbon dioxide emissions, of which cement production plays a major part, has led to interest in finding partial or complete substitutes for OPC. A major area of focus in this respect is agricultural waste ash, which tends to be carbon neutral and also possess pozzolanic properties [1]. These bio derivatives include rice husk ash, locust bean pod ash and corn cob ash, among others [1], [2], [3].

While the mechanism of soil-cement/ soil-lime stabilization is well developed, and explained in terms of cement hydration and pozzolanic reactions, it does not account for some observations being reported in literature for the observed increase in strength parameters when up to $1.5 \%$ bio-ash is added to some soils [3], [7].

\subsubsection{Statement of the Problem}

It is necessary to seek more understanding of the mechanism of bio-ash stabilization at the micro level, with a view to a better optimization of the process. This could help in reducing the nuisance of agricultural waste, in this case corn cob, as well as the carbon footprint of construction sector through partial or complete substitution of ordinary Portland cement.

\subsubsection{Aim}

To study the progressive flocculation and agglomeration of the molecules of the case study soil, upon the addition of varying blends of OPC:CCA 2:1; OPC alone; and CCA alone, all in small doses of $0-3 \%$

\subsubsection{Objectives}

The objectives of the study are:

- Determine the elemental composition of laterite soil and bio ash respectively, using Energy Dispersive X-ray Spectroscopy

- $\quad$ Determine the Unconfined Compressive Strength (UCS) of the stabilized soil at various levels doses of OPC CCA blends.

- Carry out a SEM examination of the soil stabilized progressively with OPC-CCA blends.

- Relate the lattices of the molecular structure of the various stabilized soil samples with the maximum UCS values attained and the CEC of the soil

\section{Material and methods}

\subsection{Materials}

The soil was obtained from a borrow site in the Leme area of Abeokuta $(7.03 \mathrm{oN}, 3.45 \mathrm{oE})$. It is a soil type that is generally referred to as "Laterite", widely available locally and commonly used for road construction and embankment works. It is often identified from its reddish brown colour and can be classified as silty clayey sand, in the Unified Soil Classification System.

The bio-ash for this study is corn cob ash. The corn cob was obtained from Igbo-Ora, [7.44o N, 3.29oE Long] a predominantly farming community some $20 \mathrm{~km}$ North of Abeokuta and pyro-processed at a controlled temperature of $550-600$ oC. The resulting ash was passed through the 90 micron sieve to obtain the corn cob ash used for the study.

Ordinary Portland cement grade 32.5 was obtained in the open market in Abeokuta, in the standard $50 \mathrm{~kg}$ bag.

Figure 1 is a Google Map of the Study Area 


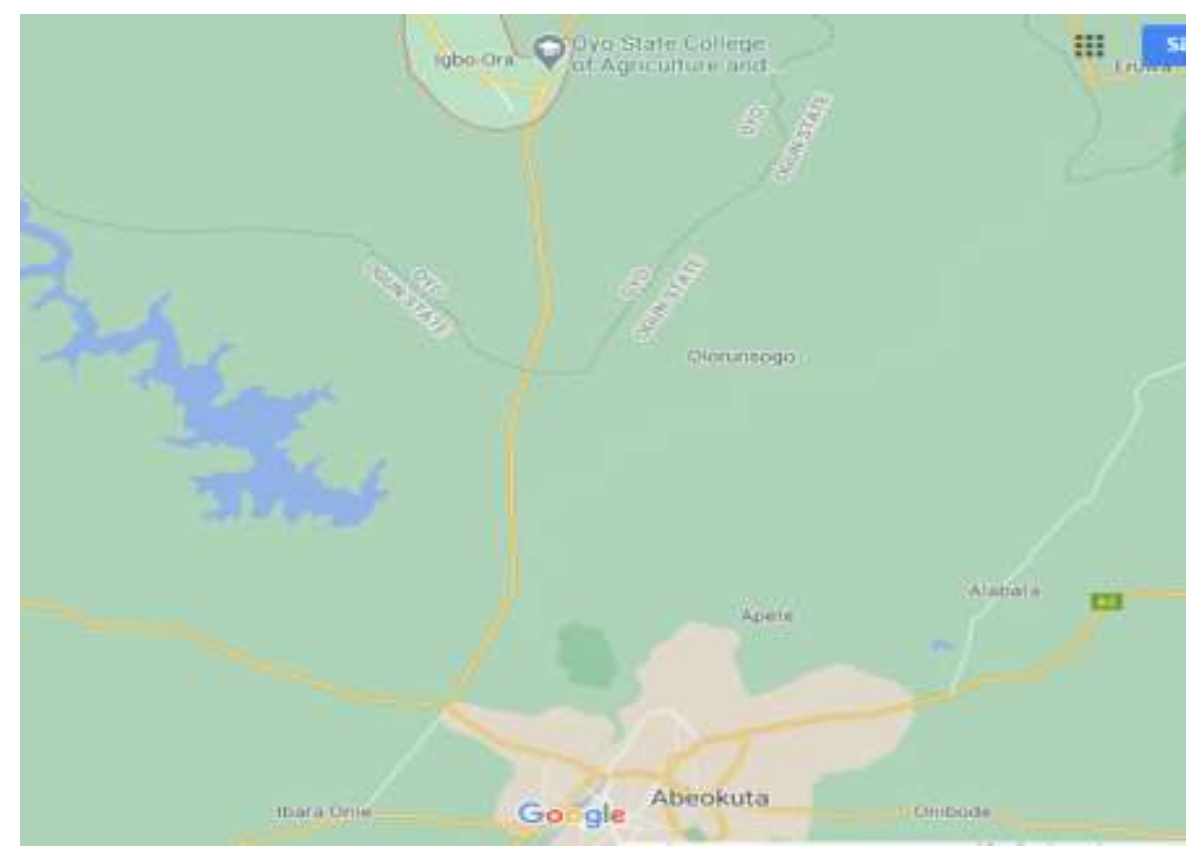

Figure 1 Google Map of the Study Area (Abeokuta and Igbo-Ora)

\subsection{Methods}

\subsubsection{Laboratory Tests}

Laboratory tests on soil, OPC, CCA and Soil/OPC/CCA mixes in various blends, were performed in two categories. The first category focused essentially on classification (Specific Gravity, Particle Size Distribution and Atterberg Limits) and strength (Unconfined Compressive Strength) and was carried out at the civil engineering laboratory of the University of Lagos, Nigeria. The second category focused on the examination of the microstructure of the tested samples using the Scanning Electron Microscope, as well as their elemental composition, by means of Energy Dispersive X-Ray Spectroscopy (EDS). It was performed at the laboratory of Department of Geology, University of Ibadan, Nigeria.

The test matrix for this study is presented in Table 1.

Table 1 Laboratory test and sample examinations

\begin{tabular}{|c|c|c|c|c|}
\hline \multicolumn{3}{|c|}{ Material Composition \% } & \multirow{3}{*}{\multicolumn{2}{|c|}{ Tests }} \\
\hline \multirow[t]{2}{*}{ Soil } & \multicolumn{2}{|c|}{ Binder } & & \\
\hline & OPC & CCA & & \\
\hline 100.00 & 0.00 & 0.00 & PSD; Specific Gravity; Atterberg Limits & \\
\hline 99.50 & 0.50 & 0.00 & UCS & XRD EDS; SEM \\
\hline 99.00 & 1.00 & 0.00 & UCS & XRD EDS; SEM \\
\hline 98.50 & 1.50 & 0.00 & UCS & XRD EDS; SEM \\
\hline 99.50 & 0.00 & 0.50 & UCS & XRD EDS; SEM \\
\hline 99.00 & 0.00 & 1.00 & UCS & XRD EDS; SEM \\
\hline 98.5 & 0.00 & 1.50 & UCS & XRD EDS; SEM \\
\hline 99.50 & 0.33 & 0.17 & UCS & XRD EDS; SEM \\
\hline 99.00 & 0.67 & 0.33 & UCS & XRD EDS; SEM \\
\hline 98.50 & 1.00 & 0.5 & UCS & XRD EDS; SEM \\
\hline
\end{tabular}

CCA = Corn Cob Ash; OPC = Ordinary Portland Cement; PSD = Particle Size Distribution; SEM = Scanning Electron Microscope; UCS = Unconfined Compressive Strength; XRD EDS = Energy Dispersive X-Ray Spectroscopy 


\section{Results and discussion}

\subsection{Physical Characterization and Elemental Composition of Soil}

The results of the physical characterization test of the soil was carried out in accordance with established procedure [5], [6], [7] is presented in Table 1, showing the soil to be A-7-6(10) material, while the elemental composition from which the cat-ion exchange capacity was subsequently computed is shown in Figure 1.

Table 1 Physical Characterization of Soil Sample

\begin{tabular}{|l|l|}
\hline Parameter & Value \\
\hline \% Passing Sieve No 200 & $48 \%$ \\
\hline Specific Gravity & 2.67 \\
\hline Liquid Limit & $48 \%$ \\
\hline Plastic Limit & $17 \%$ \\
\hline Plasticity Index & 31 \\
\hline Group Index GI & 10 \\
\hline AASHTO Classification & A-7-6 \\
\hline
\end{tabular}

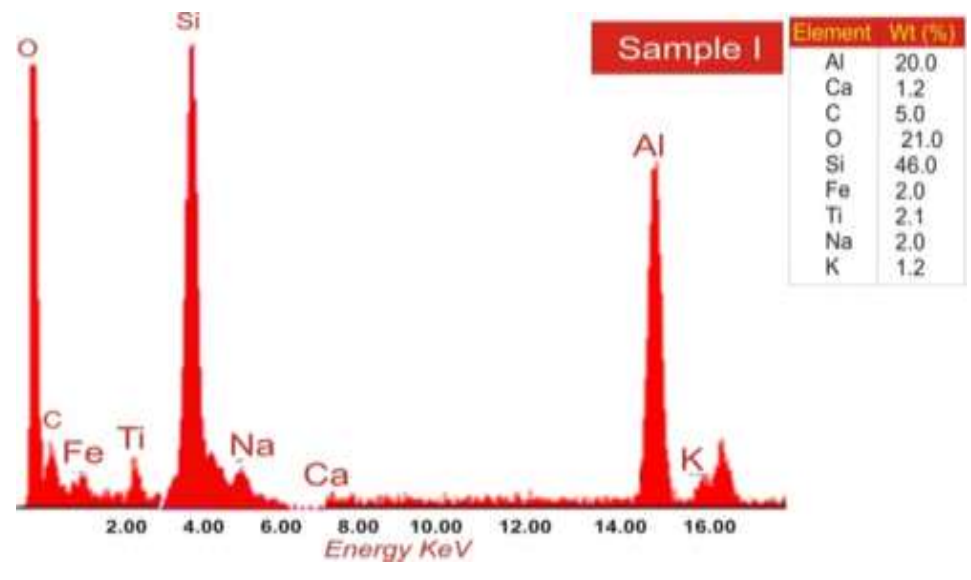

Figure 1 Elemental Composition of the Natural Soil

\subsection{Cat-ion Exchange Capacities}

From the percentage composition of the base forming cations $\mathrm{Ca} 2+$ and $\mathrm{K}+$ shown in Figure 1 , and neglecting the cation exchange capacity of the potentially acid forming cations $\mathrm{Al} 3+$ and $\mathrm{Fe} 2+$ since they are firmly held within the soil structure lattice and therefore not available for exchange [9] the cation exchange capacity was calculated using Equation 1 thus:

$\mathrm{CEC}=\Sigma[(\%$ composition of base cation $) /($ Equivalent weight $) * 100](1) \quad[8],[9],[10],[11],[12]$

The calculations are as tabulated in Table 2 . 
Table 2 Cation exchange capacity of soil sample

\begin{tabular}{|l|l|l|l|l|l|l|}
\hline $\mathbf{S} / \mathbf{n}$ & Element & $\mathbf{C a} 2+$ & $\mathbf{M g 2 +}$ & $\mathbf{N a +}$ & $\mathbf{K +}$ & CEC total \\
\hline $\mathbf{1}$ & Atomic weight (from Periodic Table) & 40 & 24 & 23 & 39 & \\
\hline $\mathbf{2}$ & Valency & 2 & 2 & 1 & 1 & \\
\hline $\mathbf{3}$ & Equivalent weight [(1)/(2)] & 20 & 12 & 23 & 39 & \\
\hline $\mathbf{4}$ & \% composition (from Fig. 1) & 1.2 & 0 & 2.0 & 1.2 & \\
\hline $\mathbf{5}$ & CEC meq/100gm [(4)/(3)*100] & 0.24 & 0 & 0.46 & 0.468 & 1.17 \\
\hline $\mathbf{6}$ & Base Saturation \% [(CEC)/(5)] & 20.51 & 0 & 39.3 & 40.0 & \\
\hline
\end{tabular}

The CEC of $1.17 \mathrm{meq} / 100 \mathrm{~g}$ is within the range of $1-3 \mathrm{meq} / 100 \mathrm{~g}$ expected of kaolinite clay and compares well with the theoretical value of $2.2 \mathrm{meq} / 100 \mathrm{~g}$ arrived at by [8] from calculations of the kaolinite microstructure.

The chemical analysis of CCA showing the elemental composition is as presented in Figure 2, while the analysis of the alkaline forming compounds ( $\mathrm{CaO}, \mathrm{MgO}, \mathrm{K} 2 \mathrm{O}$ and $\mathrm{Na} 2 \mathrm{O}$ ) able to produce exchangeable cations is presented in Table 3

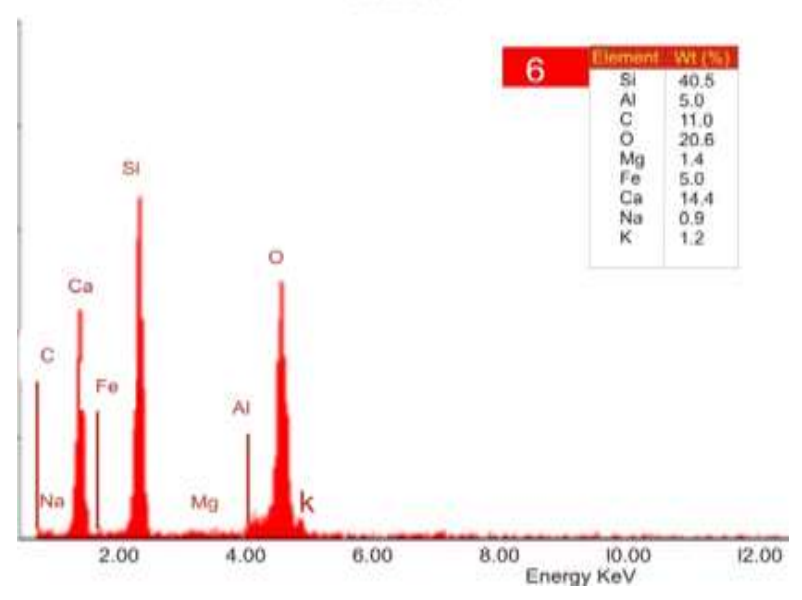

Figure 2 Elemental Analysis of CCA Sample

Table 3 Analysis of cations available for exchange in CCA

\begin{tabular}{|l|l|l|l|l|l|l|}
\hline $\mathbf{S} / \mathbf{N}$ & Element & $\mathbf{C a}^{2+}$ & $\mathbf{M g}^{2+}$ & $\mathbf{N a}^{+}$ & $\mathbf{K}^{+}$ & $\mathbf{C E C}_{\text {total }}$ \\
\hline $\mathbf{1}$ & Atomic weight (from Periodic Table) & 40 & 24 & 23 & 39 & \\
\hline $\mathbf{2}$ & Valency & 2 & 2 & 1 & 1 & \\
\hline $\mathbf{3}$ & Equivalent weight [(1)/(2)] & 20 & 12 & 23 & 39 & \\
\hline $\mathbf{4}$ & \% composition (from Figure 2) & 14.4 & 1.4 & 0.9 & 1.2 & \\
\hline $\mathbf{5}$ & CEC meq/100gm [(4)/(3)*100] & 72.00 & 11.67 & 3.91 & 3.08 & 90.66 \\
\hline $\mathbf{6}$ & Base Saturation \% [(CEC)/(5)] & 79.42 & 12.87 & 4.31 & 3.40 & \\
\hline
\end{tabular}

It can be seen from Tables II and III that the CEC for the soil sample is $1.17 \mathrm{meq} / 100 \mathrm{~g}$ and that for the CCA is $90.66 \mathrm{meq} / 100 \mathrm{~g}$, giving a ratio of of 0.013 (i.e. $1.17 / 90.66$ ) or $1.3 \%$. This ratio is the theoretical percentage of CCA in the 
soil-CCA mix, needed to just fill up the exchangeable sites of the soil. This is corroborated by reports from earlier studies [9] [10]. The two figures (1.17 meq/100 g and 1.3\%) are quite comparable indicating some sort of relationship between the two variables.

\subsection{Soil-CCA: Unconfined Compressive Strength}

Figure 5 shows the plot of Unconfined Compressive Strength (UCS) versus \% CCA content at curing times of 0, 7 and 28 days respectively. Peak UCS occurred at 1\% CCA, which compares well with the $1.3 \%$ calculated amount of bio-ash required to just fill the exchangeable sites of the soil sample. Further addition of CCA beyond this point becomes deleterious to the stabilization process. Also, while curing is certainly advantageous, no additional benefit is derived in curing beyond 7 days, as the results clearly show no difference between 7 days and 28 days UCS, both peaking at 313.7 $\mathrm{KN} / \mathrm{m} 2$

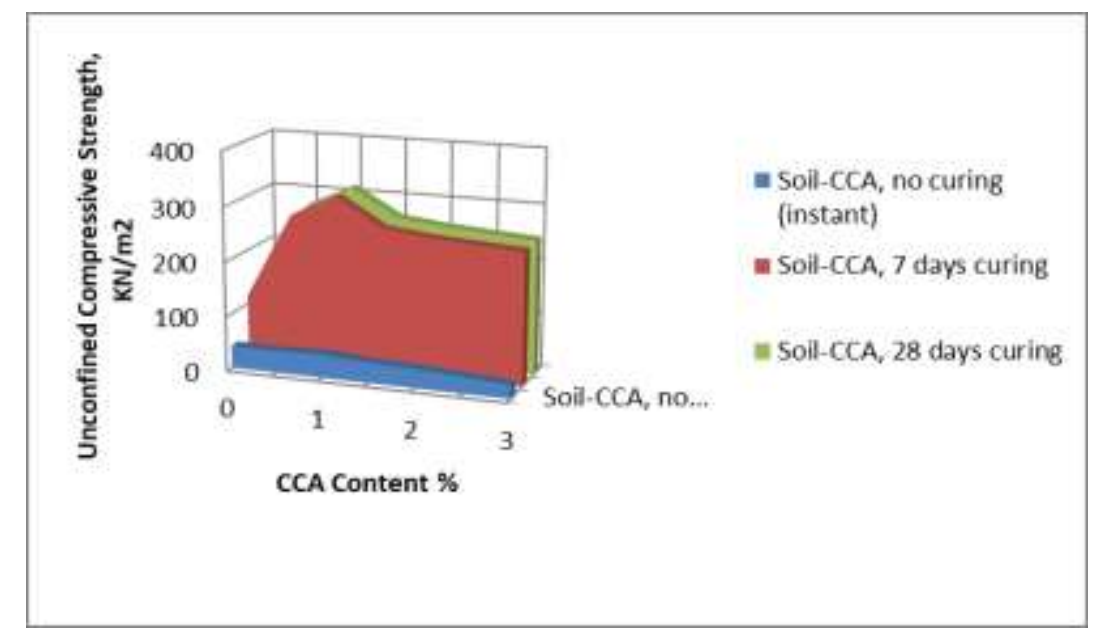

Figure 5 UCS vs CCA content for different curing periods

While these peaks are far below the strength requirements of $1800 \mathrm{KN} / \mathrm{m} 2$ [14] for pavement base course work, they could still be useful for soil improvement schemes and for other embankment works.

\subsection{Soil-CCA: Examination of the microstructure}

The images of the soil microstructure and the progressive re-arrangement of the molecules as the CCA content was increased is presented in Table $4(\mathrm{a}-\mathrm{d})$ for CCA content up to 1.5\%. The images beyond $1.5 \% \mathrm{CCA}$ are not of interest to this research work since the strength from this point on has fallen into the decline zone. The progressive re-arrangement of the clay platelets is clearly visible. In particularly the point at which the lattice structure is clearly well formed corresponds to the point of maximum strength as obtained from the UCS test results. These may be attributed to the alkaline environment provided by the bio-ash which facilitates the movement of ions, thereby promoting van der Walls type reaction and hence improved flocculation of the clay platelets. beyond the optimum point however, excess ash appears to inhibit flocculation process while the additional water content needed for compaction at higher CCA content only serves to aid the sliding the clay platelets over one another leading to a dispersed structure and hence lower strength. Similar phenomenon has been reported by Horpibulsuk et al. [14]

Table 4 Changes in soil microstructure with varying CCA content

\begin{tabular}{|c|c|c|c|c|}
\hline Soil-CCA & $0 \%$ & $0.5 \%$ & $1.0 \%$ & $1.5 \%$ \\
\hline $\begin{array}{l}\text { UCS } 28 \\
\text { days, }\end{array}$ & $\begin{array}{c}116.4 \mathrm{KN} / \mathrm{m}^{2} \\
\text { (a) }\end{array}$ & $\begin{array}{c}275.0 \mathrm{KN} / \mathrm{m}^{2} \\
\text { (b) }\end{array}$ & $\begin{array}{c}313.7 \mathrm{KN} / \mathrm{m}^{2} \\
\text { (c) }\end{array}$ & $\begin{array}{c}266.0 \mathrm{KN} / \mathrm{m}^{2} \\
\text { (d) }\end{array}$ \\
\hline $\begin{array}{l}\text { SEM } \\
\text { Image }\end{array}$ & & & & \\
\hline
\end{tabular}




\subsection{Soil - OPC: Unconfined Compressive Strength}

Figure 6 is a plot of the Unconfined Compressive Strength versus OPC content at curing times of 0, 7 and 28 days respectively. The 28 days' result appears to follow the established pattern of an active zone, followed by an inert zone, as articulated by Horpibulsuk et al. [14]. The sharp rise from 1.5\% OPC can be attributed to the cement hydration reaction, forming strong bonds between OPC and the soil particles. The UCS results are expectedly higher than that of CCA alone as shown in Figure 5. Also the well-known advantage of curing up to 28 days for cement stabilized soil is clearly manifest, with UCS of $450 \mathrm{KN} / \mathrm{m}^{2}$ and $200 \mathrm{KN} / \mathrm{m}^{2}$ at $2 \%$ OPC content for 28 and 7 days curing respectively. It is however worthy of note, that at binder dosage rates of up to 1.5\%, the UCS results for CCA as seen from Figure 5 (266 $\mathrm{KN} / \mathrm{m}^{2}$ at 28 days) are higher than those for OPC (190 KN $/ \mathrm{m}^{2}$ at 28 days) as shown in Figure 6

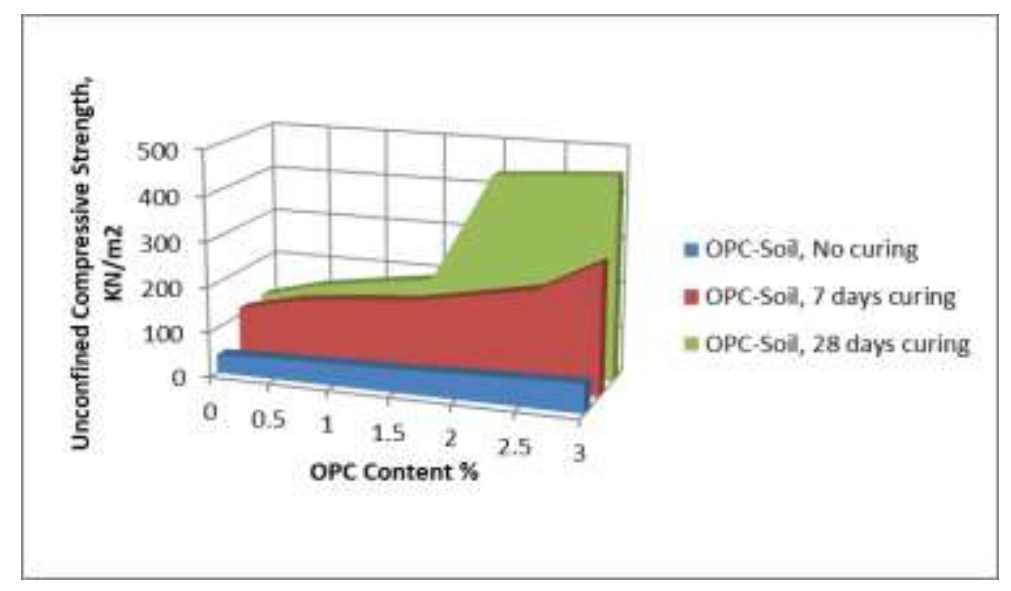

Figure 6 UCS versus OPC content at curing times of 0,7 and 28 days

It is seen that curing effect is more pronounced up to 7 days, but 28 days UCS not significantly greater 7 days

\subsection{Soil - OPC: Examination of the Microstructure}

Table 5 captures the images of the soil microstructure and the progressive re-arrangement of the molecules as the OPC content was varied from 0 to $1.5 \%(\mathrm{a}-\mathrm{d})$

Table 5 Changes in soil microstructure with varying OPC content

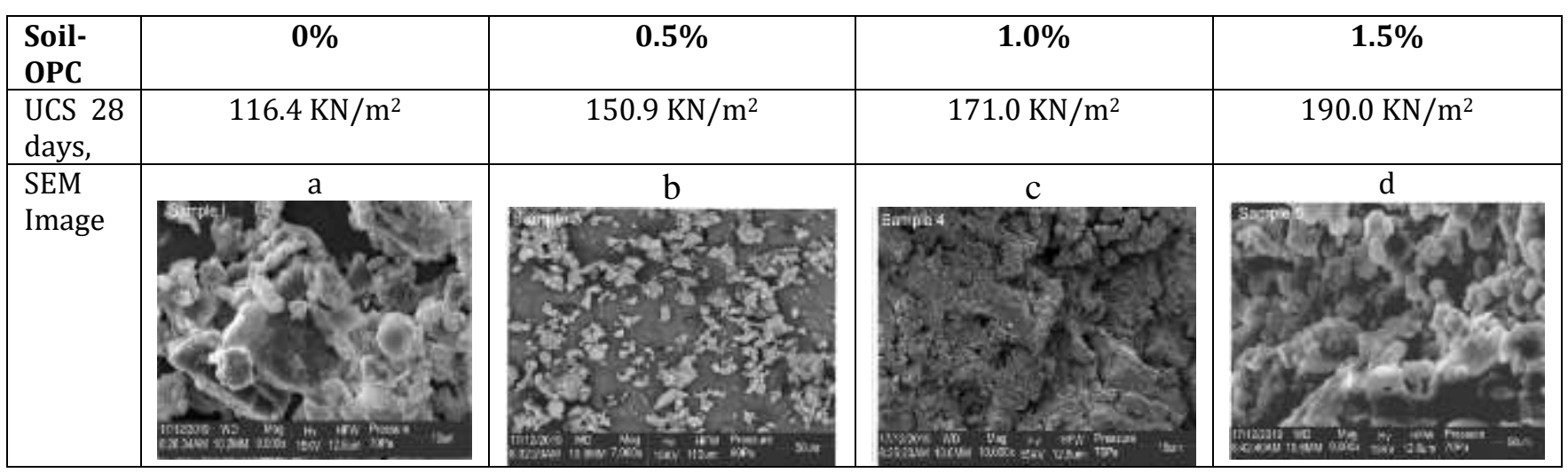

The progressive agglomeration of the soil particles into bigger lumps as the OPC content was varied from 0 - $1.5 \%$ is clearly visible. This is the established pattern for Soil-OPC stabilization [12] and it is line with the observed patter of the UCS-OPC performance graph of Figure 6

\subsection{Soil-OPC-CCA: Unconfined Compressive Strength}

Figure 7 is a plot of the Unconfined Compressive Strength versus OPC content at curing times of 0, 7 and 28 days respectively. The binder is an OPC:CCA, 2:1 blend 


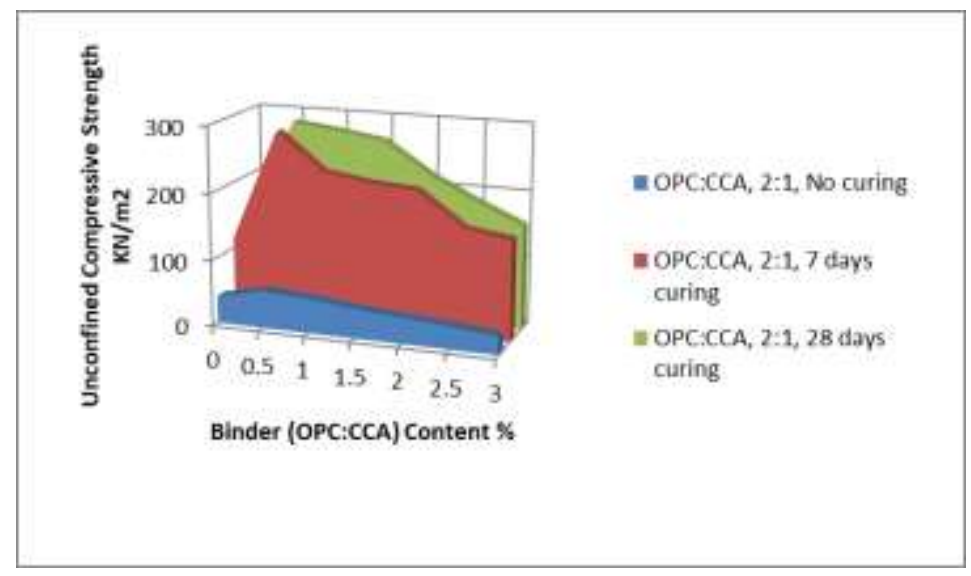

Figure 7 UCS versus Binder content at curing times of 0,7 and 28 days.

Figure 7 shows a short active zone characterized by a sharp rise in UCS from $116 \mathrm{KN} / \mathrm{m} 2$ (for both 7 days and 28 days cured samples), for the natural soil, to 146 and $151 \mathrm{KN} / \mathrm{m} 2$ for 7 days and 28 days cured samples respectively. This occurred at just $0.5 \%$ binder content, beyond which the performance curve steadily declines.

It would then appear that beyond a certain optimal amount of ash content, ash becomes deleterious to the performance of OPC as soil stabilizing agent.

\subsection{Soil-OPC-CCA: Examination of the Microstructure}

Table 6 captures the images of the soil microstructure and the progressive re-arrangement of the molecules as the OPC content was varied from 0 to $1.5 \%(a-d)$

Table 6 Changes in soil microstructure with varying binder content (OPC:CCA, 2:1)

\begin{tabular}{|c|c|c|c|c|}
\hline $\begin{array}{l}\text { Soil- } \\
\text { OPC- } \\
\text { CCA }\end{array}$ & 0\% & $0.5 \%$ & $1.0 \%$ & $1.5 \%$ \\
\hline $\begin{array}{l}\text { UCS } \\
28 \\
\text { days, }\end{array}$ & $116.4 \mathrm{KN} / \mathrm{m}^{2}$ & $285 \mathrm{KN} / \mathrm{m}^{2}$ & $276.1 \mathrm{KN} / \mathrm{m}^{2}$ & $266.0 \mathrm{KN} / \mathrm{m}^{2}$ \\
\hline $\begin{array}{l}\text { SEM } \\
\text { Imag } \\
\mathrm{e}\end{array}$ & $a$ & $\mathrm{~b}$ & & \\
\hline
\end{tabular}

It is seen from Table VI that the point at which the lattice is distinct and clearly well formed (b) corresponds to the point at which the highest UCS value of $285 \mathrm{KN} / \mathrm{m} 2$ was returned. Even though an increased agglomeration of the particles is visible at (d), this is attributed to the contribution of the OPC, which is not dominant at the range of tests conducted for this research

\section{Conclusion}

This paper investigated the potential of CCA as substitute for OPC in the stabilization of soils for road and embankment works, focusing particularly on small doses of $0-3 \%$, and the changes that take place in the micro-structure of the soil at the peak of strength, measured as UCS. The following conclusions can be drawn from this work: 
- The bio-ash effect on the clay particles is clearly pronounced at small doses of 0.5 and $1.5 \%$, which are considered quite close to the theoretically calculated cat-ion exchange capacities of $1.17 \%$ for the A-7-6 soil investigated.

- While the active zone is very short for bio-ash alone $(0-1 \%)$, it peaks at a higher value of $311 \mathrm{KN} / \mathrm{m}^{2}$, than for OPC alone and OPC-CCA blend whose active zones are $0-3 \%$ and $0-0.5 \%$, with peaks of $291 \mathrm{KN} / \mathrm{m}^{2}$ and 450 $\mathrm{KN} / \mathrm{m}^{2}$ respectively.

- The lattices of the soil-CCA structure are particularly well formed in a relative compact edge to surface structure, at $1 \%$ CCA dosage, but seem to collapse at $1.5 \%$ dosage.

- Curing up to a 7-day period clearly has a positive effect on the performance of the CCA stabilized soil. There is no strength advantage in curing beyond 7 days.

- Flocculation effects of bio-ash are apparently more pronounced when acting alone than when in combination with OPC. This was visible both in the UCS results and the microstructural investigation

\section{Recommendation}

The findings of this paper indicate a potential for the development of bio-ash as a sole soil stabilizing agent and not necessarily in combination with OPC.

A wider study that would lead to the commercial development of bio-ash as a complete substitute for OPC in the stabilization of soils is hereby recommended. This would have a positive knock-on effect on bio-waste management and anthropogenic $\mathrm{CO} 2$ contribution of the construction industry.

\section{Compliance with ethical standards}

\section{Acknowledgments}

This research work was carried with grant received from the Nigerian Tertiary Education Trust Fund (TETFUND).

\section{Disclosure of conflict of interest}

The authors whose names are listed immediately below certify that they have NO affiliations with or involvement in any organization or entity with any financial interest (such as honoraria; educational grants; participation in speakers' bureaus; membership, employment, consultancies, stock ownership, or other equity interest; and expert testimony or patent-licensing arrangements), or non-financial interest (such as personal or professional relationships, affiliations, knowledge or beliefs) in the subject matter or materials discussed in this manuscript.

Apampa O Ahmed, Oseni Kehinde and Popoola Monsuru

\section{References}

[1] Chungsangunsit T, Gheewla H, Patumsawad S. (2009) Emission Assessment of Rice Husk Combustion for Power Production. World Academy of Science, Engineering and Technology Journal. 2009; 53: 1070 - 1075.

[2] Akinwumi II, Aidomojie OI. (2015). Effect of Corncob ash on the geotechnical properties of Lateritic soil stabilized with Portland cement. International Journal of Geomatics and Geosciences. Volume 5, No 3, 2015Y.A. Jimoh, and O.A. Apampa, An evaluation of the influence of corn cob ash on the strength parameters of lateritic soils. IISTE Civil and Environmental Research. 2015; 6(5).

[3] Osinubi KJ, Oyelakin MA, Eberemu AO. (2011). Improvement of Black Cotton Soil with OPC-LBWA Blend. EJGE. 2011; 16: $619-627$.

[4] Daita KR, Drnevich VP, Kim D. (2005) "Family of Compaction Curves for Chemically Modified Soils". Publication FHWA/IN/JTRP- 2005/07. Joint Transportation Research Program, 2005, INDOT and Purdue University, West Lafayette, Indiana, US.

[5] CA O'Flaherty, Highways. (2002) The Location, Design, Construction \& Maintenance of Pavements. Elsevier Publishers. New Delhi, India.

[6] SM Agus, H Gendut. (2002) Influence of Rice Husk Ash and Lime on Engineering Properties of Clayey Subgrade. 2002.

[7] Das, B.M. Principles of Geotechnical Engineering, Cengage Learning, United States of America, 7th Edition. 2006. 
[8] C Ma, RA Eggleton (1999). Cation Exchange Capacity of Kaolinite. Journal of Clays and Clay Minerals. 1999; 47(2): $174-180$.

[9] Apampa OA, Jimoh YA. (2016). Physicochemistry of Pozzolanic Stabilization of a Class A-2-7 Lateritic Soil. International Journal of Civil, Environmental, Structural, Construction and Architectural Engineering, 2016; 10(7).

[10] M Astera. Cation Exchange Capacity Simplified. Online publication. 2007.

[11] Midwestlabs, Calculating Cation Exchange Capacity and Percent Base Saturation. Online publication. 2012.

[12] Mengel DB (2012). Fundamentals of soil cation exchange capacity. Publication of Purdue University Cooperative Extension Service, West Lafayette, USA.

[13] AASHTO (2002). AASHTO Guide for Design of Pavement Structures. American Association of State Highway and Transportation Officials. Washington DC.

[14] Suksun Horpibulsuk, Runglawan Rachan, Avirut Chinkulkijniwat, Yuttana Raksachon and Apichat Suddeepong. (2010). Analysis of strength development in cement-stabilized silty clay from microstructural considerations. Construction and Building Materials. 2010 (4): 2011-2021 